\title{
VENDOR SELECTION AND DETERMINING PROCUREMENT QUOTAS IN CONDITIONS WHEN DISCOUNTS ARE OFFERED ON THE TOTAL VALUE OF THE CONTRACTED PROCUREMENT OF MANY DIFFERENT PRODUCTS
}

\section{Zoran Babić ${ }^{1}$ \\ Tunjo Perić \\ Sead Rešić}

Faculty of Economics Split

Bakeries Sunce, Rakitje

Faculty of Science, Univerzity of Tuzla

Received: 10.03 .2012

UDC: 330.45:519.852:338.55

Accepted: 29.03.2012

\begin{abstract}
Vendor selection is a very significant business problem for ensuring the competitiveness on the market. That is why companies pay great attention to this problem. To solve the vendor selection problems can be applied to a number of quantitative methods. Depending on the goals of the company the vendor selection can be a mono-criterion or multi-criterion programming problem. This paper deals with the problem of vendor selection and determining procurement quotas from selected vendors under conditions where vendors offer discounts to the total order value within a specified period where the buyer buys more products from the vendors. The total value of procurement costs in a given period is taken as an optimization criterion. In this paper the specific flour purchase problem is solved for a company that manufactures bakery products.
\end{abstract}

Keywords: vendor selection, discounts to the total order value, mixed integer programming.

\section{INTRODUCTION}

The problem with vendor selection and determining procurement quotas from selected vendor is the most important phase for a production company in the process of procurement of materials. If all the selected vendors can completely satisfy the costumer's product needs then the process of vendor selection becomes easier, because in that case it is based solely on the vendor selection according to the criteria of the total value of procurement costs, product quality and vendor's reliability. However, the practice shows that it is not good to rely on only one vendor during the procurement. For this reason, companies sign contracts and buy materials for production from different vendors.

1 Correspodence to:

Faculty of Economics Split

Matice Hrvatske 31, Split, Croatia

E-mail: babic@efst.hr 
Apart from that, even if one vendor is the best according to all procurement criteria, the management of the company needs to procure materials for production from different vendors, which is justified by numerous strategic reasons (Beil, 2010). The number of vendors, with whom the business is handled when it comes to procuring the material for production, varies between two and five. Also, there are cases when none of the vendors can satisfy the consumer's demands or they do not want to in order to protect their business interests. In this work there is a defined situation when none of the vendors can satisfy the costumer's demands because of its limitations in capacity, quality or similar. Vendor selection is an important problem which many researches encounter. Great efforts have been put into developing suitable models for vendor selections and determining procurement quotas from selected vendors, as well as into the application of suitable methods for resolving those models. The problem with vendor selection and determining the procurement quotas from selected vendors becomes even more complex if we also take into consideration the discounts which vendors give on the total order value within a specific period. There are numerous works on that topic (Amid, Ghodsypour, and O’Brien, 2009, pp. 323332; Chaudhry, Forst, and Zydiak, 1993, pp. 5266; Jurun, Plazibat, and Babić, 1999, pp. 99-104; Kokangul \& Susuz, 2009, pp. 1417-1429; Perić, \& Babić, 2011, pp. 49-58; Wang \& Yang, 2009, pp. 12179-12187). On the other hand, only a small number or researchers dealt with the problem of vendor selection and determining the procurement quotas in cases when vendors give discounts on the total order value of various products in a specific period (Dahel, 2003, pp. 335-342; Xia \& Wu, 2007, pp. $494-504)$.
Vendor selection is according to its nature a multicriterion problem. Many works deal with the multicriterion problem of vendor selection. Also, many researchers use various methods to resolve this problem. The difference in the approaches can be seen in works: (Babić, Jurun, and Plazibat, 2001, pp. 103-110; Beil, 2010; Perić \& Babić, 2007, pp. 191-196; Perić \& Babić, 2009, pp. 1317-1342; Weber \& Current, 1993, pp. 173-184). In this work the problem of vendor selection was considered as a one-criterion problem, where the accent was given to building the model for vendor selection where the discounts on the total order value in a specific period of time are given.

Firstly, the methodology of vendor selection and determining procurement quotas of selected vendors is presented. Secondly, a methodology tested on a concrete example of vendor selection for a company that deals with the industrial production of bakery products is suggested.

\section{THE MODEL OF VENDOR SELECTION WITH DISCOUNTS ON THE TOTAL PROCUREMENT VALUE OF VARIOUS PRODUCTS}

Let us consider the situation in which a company orders $m$ of product $P_{i,} \quad i \in I=\{1,2, \ldots, m\}$ from $n$ vendor $V_{j}$, $j \in J=\{1,2, \ldots, n\}$ who offer different levels of product prices and production capacity for each product that they sell. Also, depending on the buyer's total value of procurement over a specific period of time, vendor $V_{j}$ offers a discount on the total value of procurement with the defined $r$ of discount intervals, $r \in R_{j}=\left\{1,2, \ldots, m_{j}\right\}$. In order to form a model of vendor selection which includes discounts on the total procurement value of different products, we have inserted the following signs: 
$J_{i}=$ set of vendors who offer the product $P_{i}, J_{i} \subseteq J$, $I_{j}=$ set of products offered by the vendor $V_{j}, I_{j} \subseteq I$, $D_{i}=$ quantity of the product $P_{i}$ sought by the buyer, $c_{i j}=$ unit cost of product $P_{i}$ which relates to vendor $V_{j}$,

$\varrho_{i}=$ maximum quantity of product $P_{i}$ which can be bought form vendor $V_{j}$,

$u_{j r}=$ upper limit in the interval of discount $r$ for the vendor $V_{j}$,

$u_{j r} *=$ insignificantly less than $u_{j r}$,

$d_{j r}=$ discount factor connected to the discount interval $r$ function of expenses $j$ vendor.

Variable decisions are:

$x_{i j}=$ product quantity $P_{i}$ which will be ordered from the vendor $V_{j}$,

$v_{j r}=$ total procurement value by $j$ vendor in the discount interval $r$. It should be mentioned that $v_{j r}$ $>0$ only if the procurement value from the vendor $j$ falls inside the interval $r$ and its function of expenses, in other cases it equals zero.

$y_{j r}=0$ or $1 ; 1-$ if the value of procurement form the vendor $V_{j}$ falls into the interval $r$ and its function of expenses, $0-$ in other cases.

Formulation of the model of mathematical programing is as follows:

$$
\min Z=\sum_{j \in J} \sum_{r \in R_{j}}\left(1-d_{j r}\right) \cdot v_{j r}
$$

With the equation (1) the total expenses of the procurement are minimised, where the ${ }_{d}$, represents the percentage of the discount.

Limitations:

$$
\sum_{j \in J_{i}} x_{i j}=D_{i}, i \in I
$$

With the limitation (2) we ensure that the overall demand on all products is satisfied.

$$
x_{i j} \leq Q_{i j}, i \in I, j \in J_{i}
$$

With the limitation (3) we ensure that the overall quantity of products which can be delivered by the vendor should be within the limits of their production capacities.

$$
\sum_{i \in I_{j}} c_{i j} x_{i j}=\sum_{r \in R_{j}} v_{j r}, j \in J
$$

With the limitation (4) we define the amount of the discount of the $j$ vendor.

$$
\begin{aligned}
& v_{j r} \leq u_{j r} * y_{j r}, j \in J, r=1, \cdots, m_{j}-1 \\
& v_{j m_{j}} \leq u_{j m_{j}} \cdot y_{j m_{j}}, j \in J
\end{aligned}
$$

$$
v_{j, r+1} \geq u_{j r} \cdot y_{j, r+1}, j \in J, r=1, \cdots, R_{j}-1
$$

With the limitations (5), (6) and (7) we connect the procurement of products to the discount of the total procurement value for each vendor.

$$
\sum_{r \in R_{j}} y_{j r}=1, \quad j \in J
$$

With the limitation (8) we ensure that there is only one interval of discount for each of the vendors.

$$
y_{j r} \in\{0,1\}, v_{j r} \geq 0, j \in J, r \in R_{j}
$$

$$
x_{i j} \geq 0, i \in I, j \in J_{i}
$$

With the limitations (9) and (10) we ensure integrability and non negativity for the variables of decision making.

In the upper model we can insert some additional limitations. For example, if a costumer wishes to reduce the number of vendors to let us say $K$, then it is necessary to include the following limitation instead of limitation (8):

$$
\sum_{r \in R_{j}} y_{j r} \leq 1, j \in J
$$




$$
\sum_{j \in J} \sum_{r \in R_{j}} y_{j r} \leq K
$$

As an additional limitation there can occur the limitation of the total business value with $j$ vendor to the maximum value amount $U_{j}$. This limitation is presented in the following way:

$$
\sum_{r \in R_{j}} v_{j r} \leq U_{j}, j \in J
$$

In the following chapter we will demonstrate how the model can be implemented when the problem is in the vendor selection and determining procurement quotas from selected vendors for different types of flour for a company whose business is the industrial production of bakery products.

\section{ILLUSTRATIVE EXAMPLE}

In this part of the work we will demonstrate how a suggested model can be used in determining procurement quotas from different vendors in a company whose business is the industrial production of bakery products. It should be pointed out that in the baking industry the contract for flour procurement lasts for the period of one year, from harvest to harvest. After the harvest, flour producers have the information about the available quantity of wheat, cost and quality, and that help them in defining the price, quality and quantity of the flour which they can offer in the following one-year period. That is how in the following one-year period the company plans to spend 4000 tons of flour type $550\left(P_{I}\right), 1500$ tons of flour type $850\left(P_{2}\right), 500$ tons of flour type $1100\left(P_{3}\right)$ and 1000 tons of flour type $1150\left(P_{4}\right)$, or $D_{1}=4000, D_{2}=1500, D_{3}=500$ and $D_{4}=1000$.

The company has contacted 4 potential flour vendors who, have all for themselves, defined the upper limit of the delivered quantity of all available tapes of flour, and that is presented with the matrix Q:

$$
\mathrm{Q}=\left[Q_{i j}\right]=\begin{gathered}
P_{1} \\
P_{2} \\
P_{3} \\
P_{4}
\end{gathered}\left[\begin{array}{cccc}
2000 & V_{2} & V_{3} & V_{4} \\
1000 & 1000 & 1000 & 2000 \\
500 & 500 & 500 & 1000 \\
500 & / & 500 & 500
\end{array}\right]
$$

It is visible from the matrix $Q$ that the vendor $\left(V_{2}\right)$ doesn't offer flour $P_{4}$, and that is why we have $J_{4}=\{1,3,4\}$ and $J_{1}=J_{2}=J_{3}=\{1,2,3,4\}$ set of vendors who offer the product $P_{i}$.

Similar, set of products offered by the vendor $V_{j}$ are $I_{1}=I_{3}=I_{4}=\{1,2,3,4\}$, while $I_{2}=\{1,2,3\}$. The suggested prices from each of the vendors for

\begin{tabular}{|c|c|c|c|c|c|}
\hline \multirow{5}{*}{$\mathrm{C}=\left[C_{i j}\right]=$} & & $V_{1}$ & $V_{2}$ & $V_{3}$ & $V_{4}$ \\
\hline & $P_{1}$ & 220.10 & 207.60 & 207.10 & 230.80 \\
\hline & $P_{2}$ & 200.20 & 189.12 & 192.14 & 208.16 \\
\hline & $P_{3}$ & 190.11 & 182.14 & 185.20 & 190.40 \\
\hline & $P_{4}$ & 420.25 & / & 440.70 & 430.80 \\
\hline
\end{tabular}
all types of flour are presented in the following matrix $\left(C_{i j}\right)$ :

Depending on the costumer's total procurement value within a period of one year, the vendors offer a discount expressed with $r$ interval of discount, $r \in R_{j}=\left\{1,2, \ldots, m_{j}\right\}$, and it is presented in the following table. 
Table 1. The intervals of vendor's discounts

\begin{tabular}{|c|c|c|c|c|}
\hline \multirow[t]{2}{*}{ Vendor 1} & $\begin{array}{c}\text { Procurement } \\
\text { value } \\
\text { (000 Euros) }\end{array}$ & $\mathrm{M}<100$ & $100 \leq \mathrm{M}<400$ & $400 \leq \mathrm{M} \leq 900$ \\
\hline & Discount (\%) & 5 & 8 & 10 \\
\hline \multirow[t]{2}{*}{ Vendor 2} & $\begin{array}{c}\text { Procurement } \\
\text { value } \\
\text { (000 Euros) }\end{array}$ & $\mathrm{M}<100$ & $100 \leq \mathrm{M}<400$ & $400 \leq \mathrm{M} \leq 650$ \\
\hline & Discount (\%) & 1 & 5 & 8 \\
\hline \multirow[t]{2}{*}{ Vendor 3} & $\begin{array}{c}\text { Procurement } \\
\text { value } \\
\text { (000 Euros) }\end{array}$ & $\mathrm{M}<150$ & $150 \leq \mathrm{M}<500$ & $500 \leq \mathrm{M} \leq 900$ \\
\hline & Discount (\%) & 1 & 4 & 6 \\
\hline \multirow[t]{2}{*}{ Vendor 4} & $\begin{array}{l}\text { Procurement } \\
\text { value } \\
\text { (000 Euros) }\end{array}$ & $M<100$ & $100 \leq \mathrm{M}<300$ & $300 \leq \mathrm{M} \leq 900$ \\
\hline & Discount (\%) & 3 & 5 & 10 \\
\hline
\end{tabular}

The model of vendor selection and determining the procurement quotas for the given company looks like this:

$$
\begin{aligned}
& \min Z=\sum_{j \in J} \sum_{r \in R_{j}}\left(1-d_{j r}\right) \cdot v_{j r}=0.95 v_{11}+0.92 v_{12}+0.90 v_{13}+v_{21}+0.95 v_{22}+0.92 v_{23}+ \\
& +v_{31}+0.96 v_{32}+0.94 v_{33}+0.97 v_{41}+0.95 v_{42}+0.90 v_{43} \\
& x_{11}+x_{12}+x_{13}+x_{14}=4000 \\
& x_{21}+x_{22}+x_{23}+x_{24}=1500 \\
& x_{31}+x_{32}+x_{33}+x_{34}=500 \\
& x_{41}+\quad x_{43}+x_{44}=1000 \\
& x_{i j} \leq Q_{i j}, i \in I, j \in J_{i}
\end{aligned}
$$

Taking into consideration that we have fifteen variables $x_{i j}$ in relation (3), there are also fifteen limitations that can be included in the model as the upper limits for those variables, for example Relation (4) $\sum_{i \in I_{j}} c_{i j} x_{i j}=\sum_{r \in R_{j}} v_{j r}, j \in J$ defines the $j$ vendor's discount amount, hence we have the following four limitations:

$0 \leq x_{1} \leq 2000,0 \leq x_{\text {I }} \leq 1000$, etc. 


$$
\begin{aligned}
& 220.10 x_{11}+200.20 x_{21}+190.11 x_{31}+420.25 x_{41}=v_{11}+v_{12}+v_{13} \\
& 207.60 x_{12}+189.12 x_{22}+182.14 x_{32}=v_{21}+v_{22}+v_{23} \\
& 207.10 x_{13}+192.14 x_{23}+185.20 x_{33}+440.70 x_{43}=v_{31}+v_{32}+v_{33} \\
& 230.80 x_{14}+208.16 x_{24}+199.40 x_{34}+430.80 x_{44}=v_{41}+v_{42}+v_{43}
\end{aligned}
$$

Limitations (5), (6) and (7) connect the procurement of products to the corresponding discount segment form each of the vendors. According to that we have the following twenty equations:

$$
\begin{aligned}
& v_{11} \leq 99999 \cdot y_{11}, v_{12} \geq 100000 \cdot y_{12}, v_{12} \leq 399999 \cdot y_{12}, v_{13} \geq 400000 \cdot y_{13}, v_{13} \leq 900000 \cdot y_{13}, \\
& v_{21} \leq 99999 \cdot y_{21}, v_{22} \geq 100000 \cdot y_{22}, v_{22} \leq 399999 \cdot y_{22}, v_{23} \geq 400000 \cdot y_{23}, v_{23} \leq 650000 \cdot y_{23}, \\
& v_{31} \leq 149999 \cdot y_{31}, v_{32} \geq 150000 \cdot y_{32}, v_{32} \leq 499999 \cdot y_{32}, v_{33} \geq 500000 \cdot y_{33}, v_{33} \leq 900000 \cdot y_{33}, \\
& v_{41} \leq 99999 \cdot y_{41}, v_{42} \geq 100000 \cdot y_{42}, v_{42} \leq 299999 \cdot y_{42}, v_{43} \geq 300000 \cdot y_{43}, v_{43} \leq 900000 \cdot y_{43} .
\end{aligned}
$$

Finally, we have limitation (8) which enables us to use only one discount interval for the total procurement value for each of the vendors.

Limitation (10) ensures us integrability, while limitation (11) ensures us non-negativity of the variable:

$$
\begin{aligned}
& y_{11}+y_{12}+y_{13}=1 \\
& y_{21}+y_{22}+y_{23}=1 \\
& y_{31}+y_{32}+y_{33}=1 \\
& y_{41}+y_{42}+y_{43}=1 \\
& y_{j r} \in\{0,1\}, v_{j r} \geq 0, j \in J, r \in R_{j} \\
& x_{i j} \geq 0, i \in I, j \in J_{i}
\end{aligned}
$$

\begin{tabular}{|c|c|c|c|c|c|c|}
\hline $\begin{array}{c}04-20-2011 \\
10: 32: 52\end{array}$ & \begin{tabular}{|l|} 
Decision \\
Variable \\
\end{tabular} & $\begin{array}{c}\text { Solution } \\
\text { Value }\end{array}$ & \begin{tabular}{|c|} 
Unit Cost or \\
Profit C[i] \\
\end{tabular} & $\begin{array}{c}\text { Total } \\
\text { Contribution }\end{array}$ & $\begin{array}{c}\text { Reduced } \\
\text { Cost }\end{array}$ & \begin{tabular}{|l|} 
Basis \\
Status \\
\end{tabular} \\
\hline 1 & $\times 11$ & $\mathbf{0}$ & 0 & 0 & 11,5000 & at bound \\
\hline 2 & $\mathrm{x12}$ & 2.000 .0000 & $\mathbf{0}$ & $\mathbf{0}$ & o & basic \\
\hline 3 & $\times 13$ & 2.000 .0000 & $\mathbf{0}$ & $\mathbf{0}$ & 0 & basic \\
\hline 4 & $x 14$ & o & $\mathbf{0}$ & $\mathbf{0}$ & 2,9643 & at bound \\
\hline 5 & x21 & o & $\mathbf{0}$ & $\mathbf{0}$ & 9.2536 & at bound \\
\hline 6 & $\times 22$ & 1.000 .0000 & $\mathbf{0}$ & $\mathbf{0}$ & o & basic \\
\hline 7 & $x 23$ & 446,5493 & $\mathbf{0}$ & $\mathbf{0}$ & $\mathbf{0}$ & basic \\
\hline 8 & $x 24$ & 53,4507 & $\mathbf{0}$ & $\mathbf{0}$ & o & basic \\
\hline 9 & $x 31$ & 0 & $\mathbf{0}$ & $\mathbf{0}$ & 7.3324 & at bound \\
\hline 10 & $x 32$ & 131.5260 & $\mathbf{0}$ & $\mathbf{0}$ & o & basic \\
\hline 11 & $x 33$ & o & $\mathbf{0}$ & $\mathbf{0}$ & 1.0432 & at bound \\
\hline 12 & $x 34$ & 368,4740 & $\mathbf{0}$ & $\mathbf{0}$ & 0 & basic \\
\hline 13 & $x 41$ & 500.0000 & $\mathbf{0}$ & $\mathbf{0}$ & $\mathbf{0}$ & basic \\
\hline 14 & $x 43$ & o & $\mathbf{0}$ & $\mathbf{0}$ & $\mathbf{0}$ & basic \\
\hline 15 & $x 44$ & 500,0000 & $\mathbf{0}$ & $\mathbf{0}$ & $\mathbf{0}$ & basic \\
\hline 16 & v11 & 0 & 0,9500 & 0 & 0.0300 & at bound \\
\hline 17 & v12 & $210.125,0000$ & 0.9200 & $193.315,0000$ & 0 & basic \\
\hline 18 & $\mathbf{v 1 3}$ & 0 & 0.9000 & 0 & 0 & basic \\
\hline 19 & v21 & $\mathbf{0}$ & 1.0000 & $\mathbf{0}$ & 0.0800 & at bound \\
\hline 20 & v22 & 0 & 0.9500 & o & 0 & basic \\
\hline 21 & v23 & 628.276 .1000 & 0,9200 & $578.014,1000$ & 0 & basic \\
\hline 22 & v31 & 0 & 1.0000 & 0 & 0.0896 & at bound \\
\hline 23 & v32 & 0 & 0.9600 & 0 & 0.0496 & at bound \\
\hline 24 & $\mathbf{v 3 3}$ & 500.000 .0000 & 0.9400 & 470.000 .0000 & o & basic \\
\hline 25 & v41 & 0 & 0.9700 & o & 0.1296 & at bound \\
\hline 26 & v42 & o & 0.9500 & o & 0.1096 & at bound \\
\hline 27 & v43 & 300.000 .0000 & 0.9000 & 270.000 .0000 & o & basic \\
\hline 28 & $y 11$ & 0 & 0 & 0 & 6.574 .1860 & at bound \\
\hline 29 & $y 12$ & 1.0000 & $\mathbf{0}$ & $\mathbf{0}$ & $18.000,0300$ & at bound \\
\hline 30 & $y 13$ & o & $\mathbf{0}$ & $\mathbf{0}$ & o & basic \\
\hline 31 & $y 21$ & $\mathbf{0}$ & $\mathbf{0}$ & $\mathbf{0}$ & $-18.400,0000$ & at bound \\
\hline 32 & $y 22$ & $\mathbf{0}$ & $\mathbf{0}$ & $\mathbf{0}$ & $2.999,9850$ & at bound \\
\hline 33 & $y 23$ & 1.0000 & $\mathbf{0}$ & $\mathbf{0}$ & o & basic \\
\hline 34 & y31 & o & $\mathbf{0}$ & $\mathbf{0}$ & o & at bound \\
\hline 35 & y32 & 0 & $\mathbf{0}$ & $\mathbf{0}$ & $\mathbf{0}$ & at bound \\
\hline 36 & y33 & 1.0000 & $\mathbf{0}$ & $\mathbf{0}$ & 0 & basic \\
\hline 37 & $y 41$ & o & $\mathbf{0}$ & $\mathbf{0}$ & $-34.696,0100$ & at bound \\
\hline 38 & y42 & 0 & $\mathbf{0}$ & $\mathbf{0}$ & -34.696 .0100 & at bound \\
\hline \multirow[t]{2}{*}{39} & $y 43$ & 1.0000 & $\mathbf{0}$ & $\mathbf{0}$ & o & basic \\
\hline & Objective & Function & {$[$ Min. $]=$} & $1.511 .329,0000$ & & \\
\hline
\end{tabular}

Our model has 39 variables, $\left(15 x_{i j}, 12 v_{j r}\right.$ i $\left.12 y_{j r}\right)$, and 32 limitations. The obtained model represents the model of mixed integer programming, and it has been solved with the usage of WINQSB software. The achieved results are presented in the following table.

\section{Table 2: Model solution}

From the upper table it is visible that vendor 1 delivers only the fourth type of flour in the quantity of 2000 tons $\left(x_{11}=x_{21}=x_{31}=0, x_{41}=2000\right)$.

Taking into consideration that the vendor's unit cost for that flour type is $c_{41}=420.25$, it means that the costumer's expense for the procurement of that flour type is $v_{12}=210125$ Euros, and we are in the second discount interval with an $8 \%$ discount (see table 1). Of course, $v_{11}=v_{13}=0$, while $y_{12}=1$.

For the second vendor we have $x_{12}=2000, x_{22}=$ 
$1000, x_{32}=131.526, x_{42}=0$, and because the total procurement value of that vendor is 628276.1 ( > 400000) we are in the third cost interval with the maximum discount of $8 \%$.

The third vendor delivers $2000 \mathrm{t}$ of the first flour type $\left(x_{13}=2000\right), 446.55$ t of the second type $\left(x_{23}=\right.$ 446.55), but it doesn't deliver third and four type flour $\left(x_{33}=x_{43}=0\right)$. The procurement value of that vendor is 500000 Euros; hence we are once again in the third discount interval with the maximum discount of $6 \%$. For the fourth vendor we have $x_{14}=0, x_{24}=53.45, x_{34}=$ 368.47 and $x_{44}=500$ with that vendor's total procurement value which is $v_{43}=300000$ Euros, and again we have the maximum discount of $10 \%$. The optimum value of the aimed function which expresses the total procurement expenses is 1511329 Euros.

\section{CONCLUSION}

Taking into consideration that the procurement expenses for vendors, who deliver materials for production to many companies, significantly influence the selling price of the product, the selection of the vendors has an important influence on the level of competitiveness of the company.

In this work the model of mixed integer linear programming is presented, which solves the problems concerning vendor selection and determining the procurement quotas from selected vendors in cases when the buyer buys more products from the vendors who offer discounts on the total procurement value in a specific period through a permeable interval.

A developed model, which has been verified on a real example in this work, can be generalised, and in that way successfully used in solving similar practical problems.

\section{REFERENCES}

- Amid, A., Ghodsypour, S.H. and O'Brien, C. (2009). A weighted additive fuzzy multiobjective model for the supplier selection problem under price breaks in a supply Chain, Int. J. Production Economics 121.

- Babić, Z., Jurun, E. and Plazibat N.T. (2001). A Model Approach to the vendor selection problem, Mathematical Communications, Vol. 1. No.1., Proceedings of the $8^{\text {th }}$ Conference on Operational Research - KOI 2000.

- Beil, D. R. (2010). Supplier selection, Wiley Encyclopedia of Operations Research and Management Science, edited by James J. Cochran, John Wiley \& Sons, Inc., eorms0852.

- Chaudhry, S.S., Forst, F.G. and Zydiak, J. L. (1993) Vendor selection with price breaks, European Journal of Operational Research, 70.

- Dahel, N-E. (2003). Vendor selection and order quantity allocation in volume discount environments, Supply Chain Management: An International Journal, 8/4.

- Jurun, E., Plazibat, N.T. and Babić, Z. (1999). Supplier Selection Problem in City of Split Kindergartens, Proceedings of the $5^{\text {th }}$ International Symposium on Operational Research, Preddvor, Slovenia.

- Kokangul, A. and Susuz, Z. (2009). Integrated analytical hierarchy process and mathematical programming to supplier selection problem with quantity discount, Applied Mathematical Modelling 33.

- Perić, T. and Babić, Z. (2007). A Decision System for Vendor Selection Problem, Proceedings of the $9^{\text {th }}$ International Symposium on Operational Research, Nova Gorica, Slovenia.

- Perić,T. andBabić,Z.(2009).Vendor selection byapplication of revised weighting method and fuzzy multicriteria linear programming, Proceedings of the International Scientific Conference: Challenges for Analysis of the Economy, the Business and Social Progress, Szeged, Hungary.

- Perić, T. and Babić, Z. (2011). Quantity Discounts in Supplier Selection Problem by Use of Fuzzy Multi-criteria Programming, Croatian Operational Research Review, Vol. 2.

- Wang, T-Y. and Yang, Y-H. (2009). A fuzzy model for supplier selection in quantity discount environments, Expert Systems with Applications 36.

- Weber, C.A. and Current, J. (1993). A multiobjective approach to vendor selection, European Journal of Operational Research 68.

- $\quad$ Xia, W. and Wu, Z. (2007). Supplier selection with multiple criteria in volume discount environments, Omega 35. 